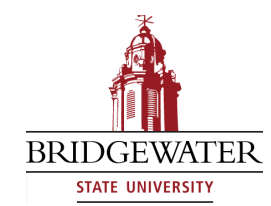

\title{
Bridgewater Review
}

Volume 16 | Issue 2

Article 7

Dec-1997

\section{The Multivisions of Multi-Culturalism}

Edward W. James

Bridgewater State College, ejames@bridgew.edu

\section{Recommended Citation}

James, Edward W. (1997). The Multivisions of Multi-Culturalism. Bridgewater Review, 16(2), 11-14.

Available at: http://vc.bridgew.edu/br_rev/vol16/iss $2 / 7$

This item is available as part of Virtual Commons, the open-access institutional repository of Bridgewater State University, Bridgewater, Massachusetts. 


\section{THE MULTIVISIONS OF MULTI-
CULTURALISM}

Edward James

A $s$ the story goes, the Lone Ranger was surrounded by hostile Indians and said, "Well Tonto, we're in a fix!"- - to which Tonto replied, "Who's the 'we' kemo sabe?" This question, "Who's the we?" is the core question of multiculturalism - and that we cannot easily answer it is the sting of multiculturalism. To properly define the we , it is essential to address questions of inclusion: Who and what is to be taught?questions of criteria: On what grounds, if any, can "we" make appraisals of "other cultures"? - questions of self-identity: When I say "we," who am I including in such august company? - questions of the meaning of multiculturalism: What is it? What is its purpose?

This discussion will thus seek to provide a framework (i) that allows us to begin a discussion that might answer such questions, (ii) that illuminates why it is that such a modest aim is the most we can hope for at this time, and (iii) that provides an understanding of what we can do in a multicultural world in order to illuminate what we should do. Let's begin by examining some of the approaches to understanding multiculturalism.

1. Muscular multiculturalism: One immediate response by many in the USA to such questions is an appeal to the ideal of tolerance - an ideal that Sir Isaiah Berlin, perhaps more than any thinker in our time, has argued for and articulated.

Berlin's central argument for toleration is that belief in the one true view has repeatedly led to disaster. In his celebrated "Two Concepts of Liberty" Berlin writes:
"One belief, more than any other, is responsible for the slaughter of individuals on the altars of the great historical ideals ... This is the belief that somewhere, in the past or in the future, in divine revelation or the mind of the individual thinker, in the pronouncements of history or science, or in the simple heart of an uncorrupted good man, there is a final solution." The belief in the One Truth, and that we have it, is in Berlin's mind the theoretical basis of the Holocaust and ethnic cleansings of our awful century. A second argument that Berlin offers for toleration is that we have no right to insist that all be educated in our way, unless we know that we are pure and good-precisely what we do not and cannot know. In his essay "Tolstoy and Enlightenment" Berlin analyzes Tolstoy's "Who Should Teach Whom to Write: We the Peasant Children or the Peasant Children Us?," where Tolstoy argued that the history of education is a history of tyranny, where each new school "struck off one yoke only to put another in its place." The scholastics pushed Greek, the language of Aristotle; Luther advocated Hebrew, the language of God; Bacon insisted on science, the language of nature. "But about one thing they were all agreed: that one must liberate the young from the blind despotism of the old; and each immediately substituted its own fanatical, enslaving dogma in its place." Further, Tolstoy sees no way out of this tyranny. While he believes that "only the pure can rescue us ... who, he reasonably asks, will educate the educators?" For us to be educated, we need to recognize the pure among us as our teachers. But to recognize the pure among us is already to be pure, is it not? So to become pure and educated we need already to be pure and educatedan impossibility. "Yet he believed that a final solution to the problem of how to apply the principles of Jesus must exist" - $a$ belief that Berlin was not able to accept. For to insist that all conform to such a faith is precisely what we must avoid, insofar as such a belief leads to terrible oppressionto none other than Dostoevski's Grand Inquisitor, the one who crucifies Christ in the name of Christ. So, Berlin, unlike Tolstoy, is left with a pessimism of necessary value conflict. As he put it in his "Two Concepts of Liberty": "The world that we encounter in ordinary experience is one in which we are faced with choices between ends equally ultimate and claims equally absolute, the realization of some of which must inevitably involve the sacrifice of others." Thus, Berlin concludes with a third argument for toleration, that it is precisely because of the lack of any universally held overarching view that we "place such immense value upon the freedom to choose," for we are willing to let no one else decide for us how we are to choose among the competing views.

Berlin presents us with a muscular multiculturalism of toleration. But the muscles Berlin flexes in the name of toleration are themselves bound by the hard hit of Tolstoy, that tolerance and its espousal of choice itself becomes just one other oppressive ideal among others. For starters, consider toleration's paradox of condescension. The ideal of toleration requires us only to "put up with" those who have different views from our own. So "we in our wisdom" allow those who are benighted enough to differ from us to express their views. But such an attitude of superiority itself soon slides into intolerance; for our sense of superiority allows us to ridicule and disdain those who would disagree with us. Berlin was willing to accept this paradox. Others are not.

2. Maximal multiculturalism: In order to avoid what Kant warned of as the "arrogant title of tolerance," others argue that multiculturalism should go beyond toleration and advocate, say, a respect for other views and cultures - or even a celebration of other views and cultures. Such views I will speak of as forms of maximal multiculturalism - the view that multiculturalism is a good and not a mere necessary evil.

Such a maximal multiculturalism can be seen in John Milton's "Areopagitica." Milton argued that to be good one had to be good knowingly, aware of the amazing convolutions of human life. First, one had to be good knowingly: A "heretic in the truth," says Milton, includes one "who believes things only because his pastor says so, or the Assembly so determines, without knowing other reason." Such a belief, even if true, is not "within" a person but is without, unstable or "movable." Second, to know one must know the amazing convolutions of human life. Truth itself is not to be simply had just because truth is not 
simple. As Osiris was cut up into a thousand pieces, so Truth has been "scattered.. to the four winds." Thus Milton dares us to answer why it is "impossible that [Truth] may have more shapes than one." The truth is that given the marvelous multifariousness of truth and the deep urge to understand that is so much a part of us, "there of necessity will be much arguing, much writing, many opinions; for opinion in good men is but knowledge in the making." As a result, those who prevent others from speaking "are the troublers, they are the dividers of unity," who "permit not others to unite those dissevered pieces which are yet wanting to the body of Truth." Consequently, diversity of views is not a matter to lament but rather a matter "to rejoice at, to praise this pious forwardness" among fellow inquirers. For "Truth is strong, next to the Almighty," and will emerge victorious through freedom of inquiry.

3. Three hard paradoxes: However, any ideal concerning multiculturalism carries the heavy baggage of three hard intertwined paradoxes - paradoxes that many see as straight-out inconsistencies.

First, there is the paradox of commitment. Are we to tolerate, respect or celebrate all ways of life? - say, the intolerant, the disrespectful and the non-celebrators of other views? And if we follow Berlin and are not tolerant of the intolerant, then are we not simply espousing our own views of what should and should not be accepted and thus adopting a stance that is antimulticultural?

Second, there is the paradox of justification. That and of what we should be tolerant, respectful, or celebratory are not self-evident and so must be justified. But any justification will be in terms of certain ideals. Consequently, will it not be the case that the ideal appealed to will be antimulticultural insofar as it insists that its brand of multiculturalism be adopted?

Finally, there is the paradox of teaching. For we in our wisdom aim to teach our students, say, to tolerate, respect, or celebrate those who differ from us. But most societies and sub-cultures do not accept toleration, respect, or the celebration of other cultures as an ideal. So are teachers to insist that their students conform to their ideal when their students have another ideal in mind? Is such an insistence multicultural?

\section{All of us have the One True View:} What implicitly follows from such paradoxes is that no matter what we say, we will do so from the perspective of the one true view. All of us, inescapably, as a matter both of logic and also of the way we live our lives, have the one true view. For instance, to insist on our fallibilism is to betray how our fallibilism is the view in terms of which one evaluates and justifies all other views. While we may look at our fallibilism critically, we do so not by asking how to radically reconstruct it but by asking how to improve ita question not foreign to any fundamental-

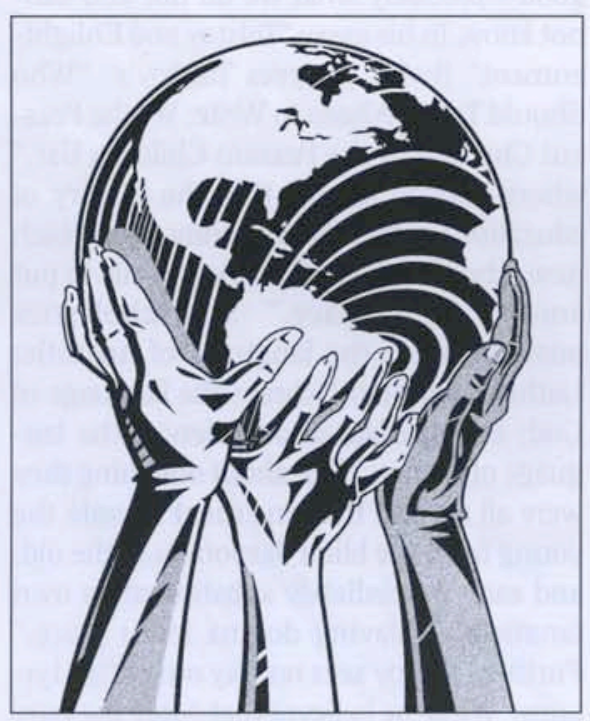

ism. Hence our fallibilism is practically speaking infallibilistic, the one true view, just because we cannot radically question it.

Thus, it turns out, we look into the mirror and behold: They are us. We, all of us, are fundamentalists in the multicultural world.

5. Minimal multiculturalism: So where do we go from here? I believe that we can return to my initial points-that it is a given that we live in a multicultural world, that we find ourselves addressing people of other cultures and vastly different perspectives, that we lack a consensus on how to address this world, and, then add: that the "we" I refer to here are those who grant these givens. Not to grant them is to be deservedly dismissed from the discussion. And an agreement on them is what I will speak of as minimal multiculturalism - what we can legitimately expect and thus demand from any other.

"But that says very little!" And indeed it does - although it took a while to see why we must say so little, why we cannot initially presume to say more. Minimal multiculturalism is the hard recognition of our small but disagreeable world. To expect more is to overlook that there is no world culture that we can appeal to in order to argue for some more benevolent form of multiculturalism. The world contains its Maos as well as its Gandhis. While we may be working toward or groping for a world culture, what that culture looks like is only a glimmer in our eyes. World multiculturalism is minimal multiculturalism.

Hence, if we are to say more and go beyond minimal multiculturalism, we must assume a more specific context than "the contemporary world." So let us narrow the context and see if we can say more by considering what it means to live in a society like that of the USA today, as found, say, in a public college.

6. Mitigated multiculturalism: For starters, as a public place in the USA, the college is composed of many many sorts of people - people who do not look alike, think alike, dress alike, eat alike. ... More, as a public college, it is engaged in a type of inquiry, which itself sets up standards of evidence, standards which lead us to the recognition that we do not always agree on what inquiry is about or even on how it is to be conducted. In a paradox, we in such a public place cannot expect us to be a we. Rather, we are an uneasy we. We are not the world: we do live in one society or nation state, a nation state with a heritage of rights and "way of doing business." But we rest uneasily in this, in that we do not agree, and never have agreed, on what "all of this" is and means.

This lack of agreement on what the we means paradoxically leads to an agreement that goes beyond minimal multiculturalism, what I will speak of as mitigated multiculturalism. The uneasy we in the USA can expect that (i) we cannot publicly assume a maximal multiculturalism, for not all of us with Milton see pluralism as a great good-as, I confess, I do; (ii) no view will be publicly regarded as sacred or closed to 
radical challenge, (iii) all views will be publicly challenged, and (iv) critics and defenders of the various views do no violence to each other-they in some way or another put up with or tolerate each other.

Why we can expect (i)-(iii) of mitigated multiculturalism to be given follows from the observation of the vast variety of people and perspectives in the USA. But why we can expect the tolerance of (iv) takes a longer story.

7. No ideal can justify mitigated multiculturalism: Crucially, we cannot justify such tolerance by any specific appeal to some ideal-a vision of how human life should be. For all ideals are in question.

Nor can we justify tolerance in terms of a heritage like the Bill of Rights, emphasizing freedom of speech, religion, and inquiry. To do so is only to beg the question. For this heritage was sharply challenged when it was first instituted, both as to what it meant and covered and also as to whether it was a good idea at all, and it is sharply challenged today.

Consider, for instance, the story that underlying the Bill of Rights was the Augustinean-Puritan ideal of the individual standing alone before God. This ideal required that all support the community's church. For the Puritans the primary right was not the right of the individual but the right of the community to worship and question as it saw fit. For such rights John Winthrop left England and Roger Williams fled Massachusetts - to form a new Republic that would worship as it, the New Republic, saw fit. Thus the Bill of Right's idea of rights as the defining core of individual as opposed to communal choice could only be seen by the purists of the Puritan tradition then and today as abominations.

And add to this story all of the other stories that inform the USA, and what results is both a reaffirmation of (i)-(iii) of mitigated multiculturalism, an appreciation of the USA as a mini-world, and also a requestioning of the tolerance of (iv) in mitigated multiculturalism. Why, to repeat, the toleration of mitigated multiculturalism?

8. Fear justifies mitigated multiculturalism: The justification of mitigated multiculturalism rests on the given that no group of the uneasy us can expect any other group to respect or welcome its Primary Truths or to remain silent about their Primary Truths. We cannot expect a Bob Jones University or, following Pope John Paul II and the USA philosopher Alasdair MacIntyre, a Roman Catholic college or university, to tolerate, let alone welcome, all views. But the uneasy we can expect that in the public arena we tolerate each other, that we put up with each other, in order to give each other a vent and thereby avoid universal war. Come what may, we, whoever we may be, will make ourselves heard. If we are prevented from making

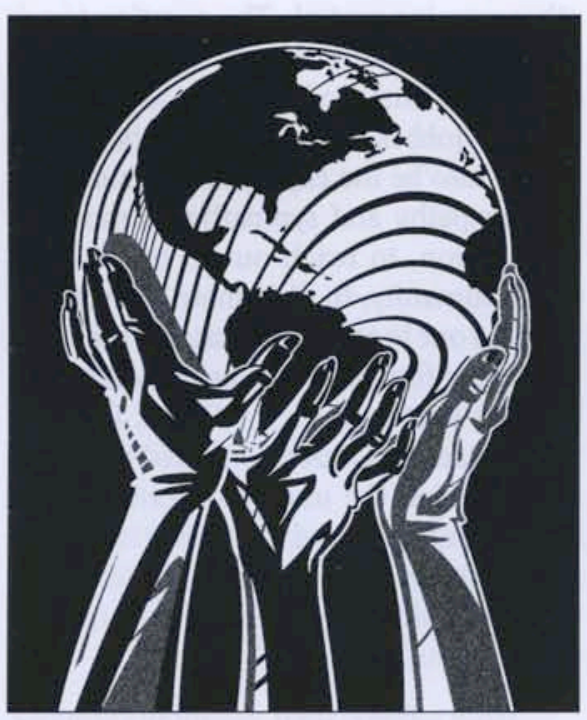

ourselves heard, what will result is a kind of war, a willingness to do each other harmwhich the uneasy we agrees must be avoided. Thus we all must be persuaded that at least this is available to us, to each and every one of us, that we can act and speak out in public arenas-provided that our acting and speaking are not violent. Such toleration is the minimum that we can expect and the maximum that we can demand in a public arena in the USA.

9. Positive and negative toleration: Mitigated multiculturalism thus distinguishes two types of toleration-positive and negative. On the one hand, positive toleration is built on some ideal or vision of how human life should be lived-e.g., Berlin's centrality of individual choice, or John Stuart Mill's idea of unrestricted inquiry. On the other hand, negative toleration is built on no such affirmation of hu- man possibility, but on a fear of others and the horrible consequences that will result if they are denied their say.

Negative toleration is hardly a positive ideal, one that each party celebrates, but is unwelcome in at least four ways. First, it is unwelcome in that it is justified by fear of others and what bad things they can and will do to us if they are prevented from expressing themselves. Second, it is unwelcome in that it has force only when the other has power and is willing to use it. It thus charges us all to be on our guard against those who would deny it to us and warns that we must rely on ourselves to protect our core ideals. Third, it is unwelcome in that it represents a failure - either our failure to make the other see our One Truth, or, more likely to be said, the other's failure to accept our One Truth. And finally, it is unwelcome in that it is not an end in itself, some ideal or vision to embrace, but a mere means to an end. It allows us to live, not together as one, but side by side yet apart, as we seek to find ways of getting the other to see. It allows us to carry on war by other means.

10. Negative toleration sidesteps the paradoxes of positive toleration: The negative toleration of mitigated multiculturalism avoids the four paradoxes that plagued positive toleration - by not allowing them to arise. It does not allow them to arise just because it does not view itself as something good in itself.

First, it sidesteps the paradox of condescension by not deigning to tolerate the other out of any superior ideal but by being forced to tolerate the other out of fear-a kind of respect. It slides by the paradox of commitment by not being committed to toleration as an ideal, but by being committed to one's own self-expression. It dodges the paradox of justification by rejecting the notion that the justification of toleration must be in terms of certain idealsideals which it inflicts on others. Fear of the other is no ideal to be attained but is brute reality to be addressed. And finally, it finesses the paradox of teaching by claiming that negative toleration is no superior view to be taught but rather an inferior position to be endured. 
11. The paradox of mitigated multiculturalism: Nonetheless, from these considerations follows mitigated multiculturalism's own paradox: it is what we can all agree on and what no one wants. No one wants it, moreover, not only because it is unwelcome in the four above-mentioned ways, but also because of its resemblance to that stark Hobbesian understanding of human motivation and of government-where all of us seek to advance our own self interest merely because it is our own self-interest, so that we will advance our own self-interest in whatever way we can. Hence, if we have the might we have the right, the reason of self-interest, to do whatever we will-whether that be lying, cheating, maiming, or brutalizing othersto advance our interests. Consequently, almost all of us, even those of us who are in power, take great pains to persuade others that they are not working just out of selfinterest alone, but rather have other reasons or ideals to restrain and guide them.

But what these other reasons or ideals are, why we are not to run rampant over the interests of others when it is in our selfinterest to do so and we can "get away with it," and what these reasons themselves entail remain much in question. The sheer number and force of the reasons as to why most reject Hobbes as the last word reinforces the necessity of mitigated multiculturalism's negative tolerance. Just because most cannot agree on why Hobbes is to be rejected, and just because each competing reason as to why Hobbes is to be rejected carries with it profound social consequences, we need a Hobbesian grounding to society with respect to free speech and human expression to protect ourselves from those who would surpass Hobbes. Such a grounding satisfies no one.

12. A more complete and hopeful mitigated multiculturalism: If we are all agreed that Hobbes is unsatisfactory and must be surpassed, might this offer us further guidance?

Well, as a start, this agreement that we want to go beyond the negative tolerance of mitigated multiculturalism entails a further agreement to seek out and explore ways to go beyond it - even by the uneasy us. For if we are committed to the idea that Hobbesian negative tolerance must be surpassed and that we cannot surpass Hobbes by forcing our views on others-for that would only reinforce the grim Hobbesian worldthen what follows is the necessity of us, the uneasy us, engaging in the hard discussion of how we can surpass Hobbes. And this question in turn leads us to ask how the uneasy we can become a less uneasy we.

Such an exploration of how we can become less uneasy with each other will involve seeking new ways of putting up with each other that are not out of fear. One tack I believe it will take is that of questioning the idea of power. For Hobbes' observation that we are moved to the spirit of accommodation by a respect for the power of the other remains central. The question to ask is whether power is merely the capacity to control, to hurt, and to harm, as we see it work in Hobbes. We can ask whether power might also be the capacity to persuade, to gain empathy and sympathy, to move by compassion, to reach out to others with one's humanity, to illuminate the reasons that lead one to adopt with passion the views one has, to force others to listen by the logic of one's language, .... Power, in other words, itself is a much contested notiona notion that the uneasy we can perhaps agree is much in need of redefinition in our multicultural world, on pain of being reduced to Hobbes' world of mutual and universal distrust.

What follows, then, is a more complete definition of mitigated multiculturalism(i) that we cannot publicly assume a maximal multiculturalism; that we can expect that (ii) no view will be publicly regarded as sacred or closed to fundamental questioning, (iii) that all views will be publicly scrutinized and challenged, (iv) that critics and defenders of the various views do no violence to each other-that they in some way or another put up with or tolerate each other out of fear of each other; and, finally, (v) that (a) this negative toleration is unwelcome to all and (b) we all seek ways of surpassing it-perhaps by imagining notions of power that go beyond brute force and even touch on sympathy, respect, compassion, human solidarity.

Such a multiculturalism, mitigated as it is, may allow us the intellectual framework to build the new world the uneasy we say we seek. But it will have to be con- structed context by context, culture by culture, country by country. For I suspect that French Egalitarianism, German Volk and Blut, English nobility and commoner, Indian secularism and sects, ..., will all draw strikingly different slants than the stories of multiculturalism made in the USA.

Further, if and when the world gets smaller, if and when it becomes more and more clear that we live in the world as we live in our country, then minimal multiculturalism might be reconceived as mitigated. But how to get us, all of us, to live in the world as we live in our country is currently beyond our reach. For while we all may agree that toleration out of fear is not enough, we do not agree that the world is our country. We in the world still do not have to tolerate each other in the way that we in the USA must tolerate each other. Perhaps as the world becomes more and more polluted and the resources of the world more and more depleted, so that the powerful of the world can no longer escape the hardships that most face on a day to day basis,... But all of this is another story.

In any case, ideally the public college uniquely stands as a safe haven and crucible, a sustained experiment in critically and imaginatively understanding and expressing power, where many cultures and visions may interact without doctrinaire restraint or violence. In this it sets a standard for all the world to see: it ideally is the guaranteed arena of unrestricted self-reflective non-violent inquiry. It is an exciting place to be. And I am glad to be a part of it. $\mathrm{s}$

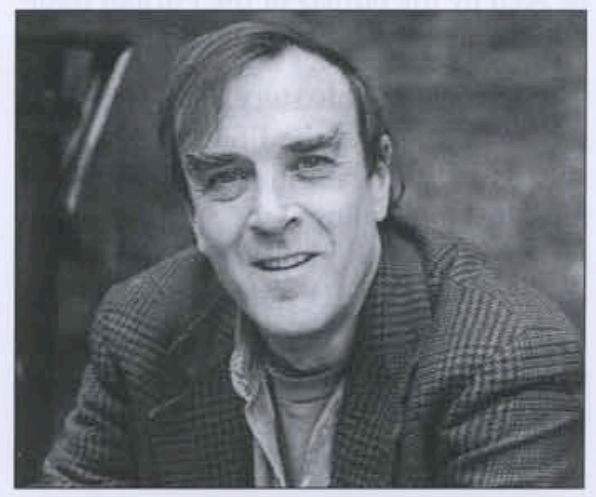

Edward James is Professor of Philosophy 